\title{
A Durability Study on Automotive Disk Brake by Shape through Simulation Analysis
}

\author{
Kye-KwangChoi' and Jae-Ung Cho ${ }^{2^{*}}$ \\ 'Department of Metal mold Design Engineering, Kongju National University, 1223-24, CheonanDaero, \\ Seobuk-gu, Cheonan-si - 31080, Chungnam, Republic of Korea; ckkwang@kongju.ac.kr \\ 2Department of Mechanical and Automotive Engineering, Kongju National University, 1223-24, CheonanDaero, \\ Seobuk-gu, Cheonan-si - 31080, Chungnam, 31080, Republic of Korea; jucho@kongju.ac.kr
}

\begin{abstract}
Objectives: As traffic accidents have been increased at driving, this paper aims at obtaining the information for the safe design of disk brake in order to prevent and reduce these accidents. Methods/Statistical Analysis: The brake system among these devices is the most important element in automobiles capable of preventing or reducing traffic accidents. For such brake system, disk brakes are currently being used most universally. However, at driving on harsh environments such as high temperature and pressure due to sliding friction, the sturdy durability is an essential requirement. Thus, the simulation structural analyses were performed by the finite element analysis in this study. Findings: The deformation, equivalent stress, fatigue life and durability of each disk brake model are found through this study result. By comparing with one automotive disk brake model, the maximum equivalent stress becomes larger and the maximum fatigue life becomes shorter at the automotive disk brake model of another shape. So, the additional studies such as the design change or the reinforcement are considered necessary at the automotive disk brake model of another shape. In the cases of one car disk brake model and car disk brake model of another shape, the maximum fatigue lives was shown to be about 1,171,000 cycles and 336,930 cycles respectively. The damage ratio in the case of the car disk brake model of another shape was shown to be about $6.75 \%$ as the maximum, whereas the damage ratio was shown to be about $3.16 \%$ as the maximum in the case of one car disk brake model, affirming that durability for the disk brake model of another shape was vulnerable. Improvements/Applications: The data derived though this study is thought to be utilized for the design of the disk brake having an improved durability as compared with one car disk brakes.
\end{abstract}

Keywords: Automotive Disk Brake, Durability, Equivalent Stress, Fatigue Life, Shape, Total Deformation

\section{Introduction}

As a result of increased ownership for automobiles by people due to today's popularization of automobiles, traffic accidents are on the rise. To prevent and reduce these accidents, the measures on the national level are being designed, and the automobile companies are making much effort for development of safety devices such as braking apparatus, air bag, etc. The braking apparatus among these devices is the most important element in automobiles capable of preventing or reducing traffic accidents $\frac{1-3}{}$. For such brake system, disk brakes are currently being used most universally, decelerating or stopping the automobile by converting its kinetic energy to thermal energy in a short time. However, it is operated under considerably harsh environments such as high temperature and pressure, etc. due to sliding friction.

${ }^{*}$ Author for correspondence 
So, the sturdy durability is an essential requirement. Thus, in this study, simulation structural analyses were performed by ANSYS finite element analysis program through $3 \mathrm{D}$ modelling with reference to the disk brakes being sold in the market, and its contribution was to be made to the design of safe disk brakes by studying the durability of each disk brake based on the derived result values ${ }^{4-7}$.

\section{Research Models}

In this study, a total of two types of car disk brake models including one car disk brake model and the car disk brake model of another shape were subjected to $3 \mathrm{D}$ modelling by using CATIA design program as shown in the following Figure 1, with reference to the car disk brakes being sold in the market. Also, the material for the two disk brake models was a structural steel, whose material properties are given in the following Table 1.

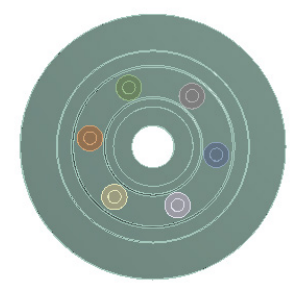

(a) One car brake disk model

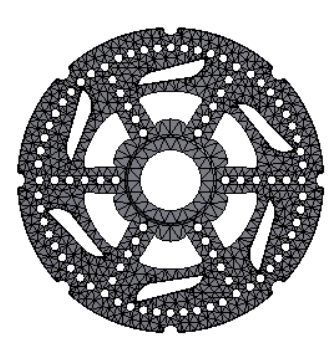

(b) Car disk brake model of another shape

Figure 1. Configurations of car disk brake models.

Table 1. Property of material

\begin{tabular}{|l|c|}
\hline Material & Structural steel \\
\hline Density $\left(\mathrm{kg} / \mathrm{m}^{3}\right)$ & 7850 \\
\hline Young's Modulus $(\mathrm{GPa})$ & 200 \\
\hline Poisson's Ratio & 0.3 \\
\hline Yield strength $(\mathrm{MPa})$ & 250 \\
\hline Ultimate strength $(\mathrm{MPa})$ & 460 \\
\hline
\end{tabular}

\section{Research Method}

Figure 2 shows the boundary conditions applied to the car disk brake models per shape. First, $200 \mathrm{~N}^{\star} \mathrm{mm}$ of turning moment was applied by assuming the moment due to tire turning and imposing the moment condition after the fixed support condition was imposed on the part fixed to the shaft for fixing in the case of one car disk brake model, and the pressure condition of 500Pa was imposed by assuming the pressure happened in the disk brake. Next, in the case of the disk brake model of another shape, the fixed support condition was similarly imposed to the part fixed to the shaft, with the fixed support condition being imposed for fixing by assuming that the tip parts on both sides of model 1 and model 2 were fixed to the frame of the car, and the turning moment of $3000 \mathrm{~N}^{*} \mathrm{~mm}$ was applied by assuming the turning moment due to tire and imposing the moment condition with the pressure of $1000 \mathrm{~Pa}$ by assuming the pressure happened in the disk brake. Through this analysis, the durability of disk brake models was to be studied in terms of total deformation, equivalent stress distribution and fatigue life, etc. for the car disk brake models according to shape.

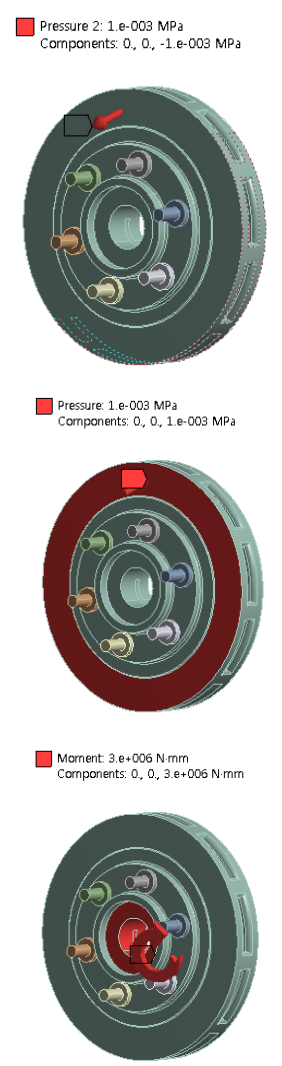

(a) Onecar disk brake model 


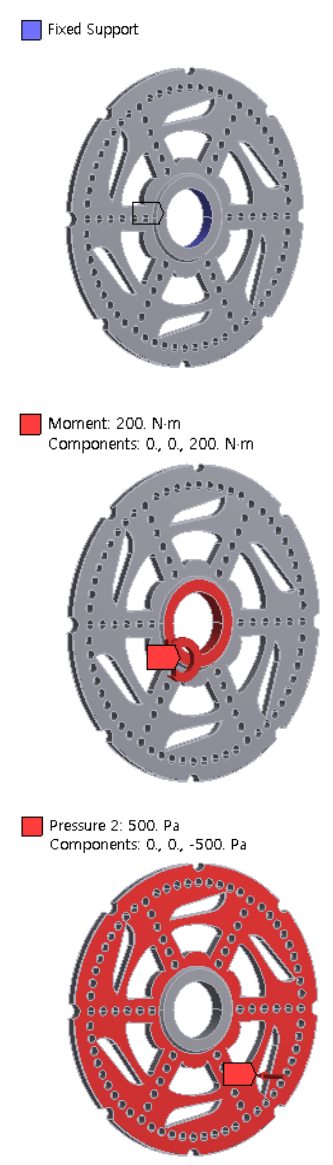

(b) Car disk brake model of another shape

Figure 2. Boundary conditions of car disk brake models.

\section{Simulation Analysis Results}

Figures 3 and 4 schematically shown represent the simulation structural analysis results for one car disk brake model and the car disk brake model of another shape, respectively, showing total deformations of each car disk brake model. As the results of a simulation analysis, the maximum total deformation for one car disk brake model was shown to be about $0.0212 \mathrm{~mm}$, and about $0.00483 \mathrm{~mm}$ in the case of the car disk brake model of another shape. When the models were compared with each other, the maximum total deformation for the car disk brake model of another shape was observed to be smaller than that for one car disk brake model. Also, the maximum total deformations for both of one car disk brake model and the car disk brake model of another shape were affirmed to occur widely around the outside part as the center.

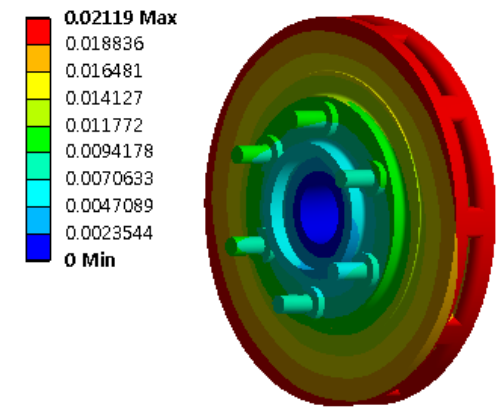

Figure 3. Total deformation of onecar disk brake model.

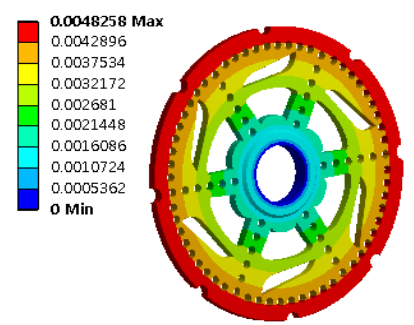

Figure 4. Total deformation of anothershape car disk brake model.

Figures 5 and 6 represent the simulation structural analysis results, showing the equivalent stress distributions for the car disk brake models. According to the analysis results, the maximum equivalent stress for one car disk brake model was shown to be about 58.67MPa, while the same state happened in the car disk brake model of another shape was shown to be about 91.62MPa. When a comparison was made on the basis of the corresponding results, the maximum equivalent stress for one car disk brake model was shown to be smaller than that for the car disk brake model of another shape on the contrary to the comparison of the maximum total deformations. However, the stress distributions for both types of the car disk brake models showed a similar aspect, and the additional studies along with redesigns are considered necessary for considering the model of another shape designed for alleviation of stress concentration.

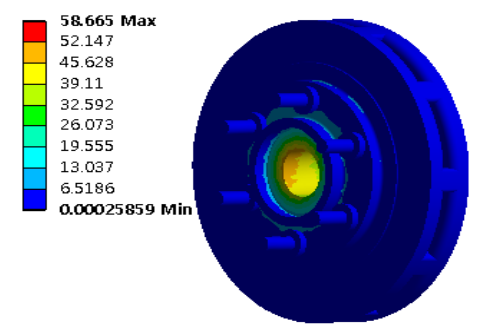

Figure 5. Equivalent stress of onecar disk brake model. 


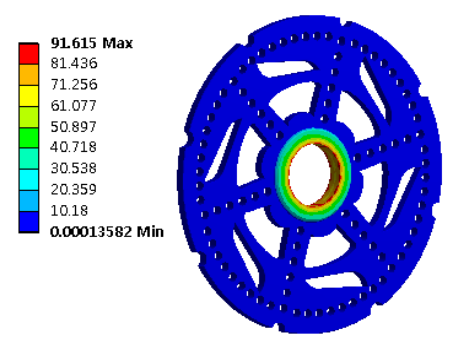

Figure 6. Equivalent stress of anothershape car disk brake model.

Figures 7 and 8 represent the simulation analysis results for each car disk brake model, showing the maximum fatigue lives for the respective car disk brake models. In the case of one car disk brake model, the maximum fatigue life was observed to be about 1,171,000 cycles, and that for the car disk brake of another shape about 336,930 cycles. Since the magnitude of the maximum stress happened was shown to be large in comparison with that for one car disk brake model, the maximum fatigue life was shown to be shorter, through which the redesign or reinforcement was shown to be required for the car disk brake model of another shape. Also, Figures 9 and 10 show the graphs of the relative damages and the results happened in each car disk brake at fatigue analysis. Whereas such damage ratio was shown to be about $3.16 \%$ as the maximum in the case of one car disk brake model, the same state in the case of the car disk brake model of another shape was shown to be about $6.75 \%$ as the maximum, so that the car disk brake model of another shape can be seen to be more vulnerable as compared with one car disk brake model.

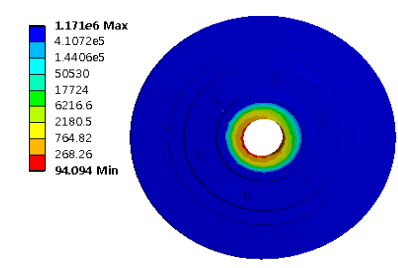

Figure 7. Fatigue life of onecar disk brake model.

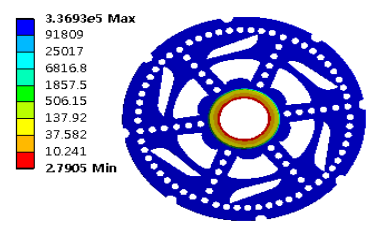

Figure 8. Fatigue life of anothershape car disk brake model.

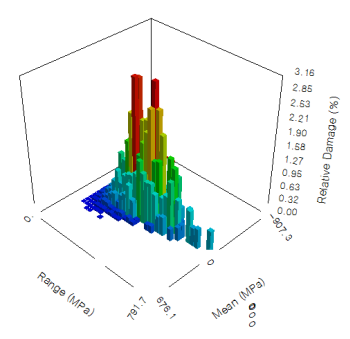

Figure 9. Damage matrix of onecar disk brake model.

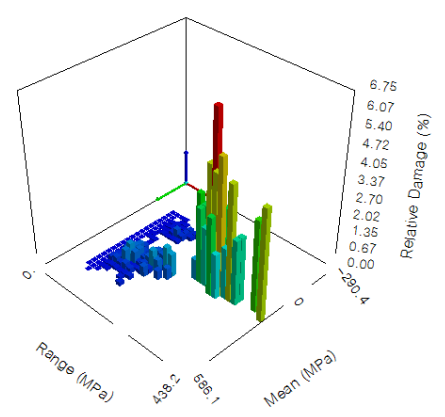

Figure 10. Damage matrix of anothershape car disk brake model.

\section{Conclusions}

In this study, simulation structural analyses were performed for the car disk brake models according to shape, and the following conclusions have been drawn:

1. In the case of one car disk brake model, all comparison variables such as the maximum equivalent stress, the maximum fatigue life excluding the maximum total deformation were shown to be smaller than those for the car disk brake model of another shape.

2. In the case of the car disk brake model of another shape, all comparison variables such as the maximum equivalent stress, the maximum fatigue life excluding the maximum total deformation were shown to be larger than those for one car disk brake model so that additional studies such as design change or reinforcement, etc. are considered necessary for another design to alleviate stress concentration.

3. In the case of one car disk brake model, the maximum total deformation was shown to be about $0.0212 \mathrm{~mm}$, the maximum equivalent stress about $58.67 \mathrm{MPa}$, and the maximum fatigue life about 1,171,000 cycles. In the case of car disk brake model of another shape, the maximum total deformation was shown to be about $0.00483 \mathrm{~mm}$, the maximum equivalent stress about 
91.62 $\mathrm{MPa}$, and the maximum fatigue life 336,930 cycles. Also, as can be seen in the damage matrix, the damage ratio in the case of the car disk brake model of another shape was shown to be about $6.75 \%$ as the maximum, whereas the damage ratio was shown to be about $3.16 \%$ as the maximum in the case of one car disk brake model, affirming that durability for the disk brake model of another shape was vulnerable.

4. It is considered that the data derived though this study can be utilized for design and development of the disk brakes having an improved durability as compared with the existing car disk brakes.

\section{References}

1. Kim B, Kim T, Song H. Parallel and distributed framework for standalone monte carlo simulation using mapreduce. Indian Journal of Science and Technology. 2015; 8(25):1-8.

2. Yin C, Zhang Z, Wang Z, Guo H. Numerical simulation and experimental validation of ultrasonic de-icing system for wind turbine blade. Applied Acoustics. 2016; 114(15):19-26.
3. Yan S, Yang H, Li H, Yao X. Variation of strain rate sensitivity of an aluminum alloy in a wide strain rate range: Mechanism analysis and modeling. Journal of Alloys and Compounds. 2016; 688(15):776-86.

4. Tolosana N, Ranz D, Gracia O, Cuartero J, Miravete A. A micromechanical composite approach for finite element crashworthiness simulation. Mechanics of Advanced Materials and Structures. 2016; 23(12):1430-36.

5. Palm J, Eskilsson C, Paredes G, Bergdahl L. Coupled mooring analysis for floating wave energy converters using CFD: Formulation and validation. International Journal of Marine Energy. 2016; 16(1):83-99.

6. Wen J, Ju W, Han T, Choi S, Lee K. Finite element analysis of a subsurface penny-shaped crack with crack-face contact and friction under a moving compressive load. Journal of Mechanical Science and Technology. 2012; 26(9):2719-26.

7. Mohammed S, Devaraj D, Ahamed T. Modeling, simulation and analysis of photovoltaic modules under partially shaded conditions. Indian Journal of Science and Technology. 2016; 9(16):1-8. 